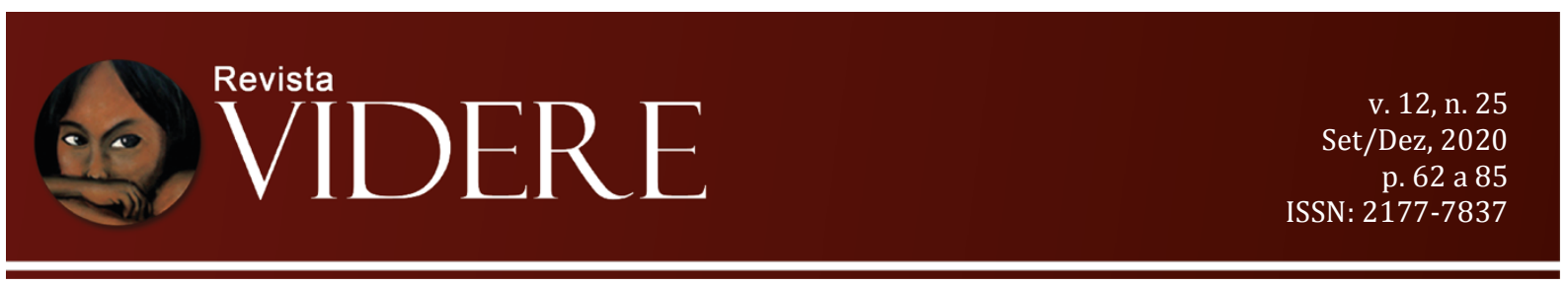

\title{
JUSTIÇA E IGUALDADE PARA PESSOAS COM DEFICIÊNCIAS: A DEFICIÊNCIA COMO UMA DAS FRONTEIRAS DA JUSTIÇA DE RAWLS
}

\author{
JUSTICE AND EQUALITY FOR PEOPLE WITH DISABILITIES: DISABILITY AS ONE \\ OF RAWLS' FRONTIERS OF JUSTICE
}

JUSTICIA E IGUALDAD PARA LAS PERSONAS CON DISCAPACIDAD: LA DISCAPACIDAD COMO UNA DE LAS FRONTERAS DE LA JUSTICIA DE RAWLS

\begin{abstract}
Luana Adriano Araújo Doutoranda em Direito pela Universidade Federal do Rio de Janeiro. Mestre em Direito Constitucional pela Universidade Federal do Ceará. Universidade Federal do Rio de Janeiro, Rio de Janeiro, Brasil luanaadriano@ufrj.br OrcidID: 0000-0002-6761-837X
\end{abstract}

\begin{abstract}
Resumo: Pessoas consideradas como não-cooperativas, com funcionamentos anormais, abaixo de uma linha de capacidades básicas ou dependentes têm sido tradicionalmente excluídas do manto da justiça. Em atenção a esse problema, nosso objetivo é analisar o conceito de justiça de Rawls no tocante à inclusão de pessoas com deficiência, tanto no momento da composição da justiça, no consenso hipotético da posição original, quanto no momento da aplicação das regras da justiça arquitetada. Identificamos quatro clivagens da teoria de justiça rawlsiana que impedem o acolhimento da deficiência: o véu da ignorância cominado com a igualdade hipotética; o leque normal de variação; as desigualdades naturais consideradas no princípio da diferença; e a conceituação de "pessoas éticas". Em um segunda incursão, relatamos as críticas de Kittay, no âmbito da ética do cuidado e da interdependência, e de Nussbaum, no contexto da abordagem das capacidades. Nossa metodologia é hipotéticodedutiva, com abordagem qualitativo-descritiva e com aporte na revisão bibliográfica.
\end{abstract}

Palavras-chave: Justiça. Igualdade. Pessoas com Deficiência. Cuidado. Capacidades.

Abstract: People considered as non-cooperative, with abnormal functioning, that stand below a line of basic capacities have traditionally been excluded from the mantle of justice. Concerning this problem, our objective is to analyze Rawls' concept of justice with regard to the inclusion of people with disabilities, both when composing justice, in the hypothetical consensus of the original position, and when applying the rules of architected justice. We identified four cleavages in the Rawlsian theory of justice that prevent the reception of 
disability: the veil of ignorance combined with hypothetical equality; the normal range of capacity's variation; the natural inequalities considered in the difference principle; and the concept of "ethical people". In a second foray, we report the criticisms of Kittay, in the scope of the ethics of care and interdependence, and of Nussbaum, in the context of the capabilities approach. Our methodology is hypothetical-deductive, with a qualitative-descriptive approach and it is based on a bibliographic review.

Keywords: Justice. Equality. People with Disabilities. Care. Capabilities.

Resumen: Las personas consideradas no cooperativas, con funcionamiento anormal, por debajo de una línea de capacidades básicas o dependientes han sido tradicionalmente excluidas del manto de la justicia. Ante esta problemática, nuestro objetivo es analizar el concepto de justicia de Rawls en cuanto a la inclusión de las personas con discapacidad, tanto a la hora de componer la justicia, en el hipotético consenso de la posición original, como al aplicar las reglas de la justicia arquitectónica. . Identificamos cuatro divisiones en la teoría de la justicia rawlsiana que impiden la recepción de la discapacidad: el velo de la ignorancia combinado con la igualdad hipotética; el rango normal de variación; las desigualdades naturales consideradas en el principio de diferencia; y el concepto de "personas éticas". En una segunda incursión, reportamos las críticas a Kittay, en el ámbito de la ética del cuidado y la interdependencia, y de Nussbaum, en el contexto del enfoque de capacidades. Nuestra metodología es hipotético-deductiva, con un enfoque cualitativo-descriptivo y basada en una revisión bibliográfica.

Palabras clave: Justicia. Igualdad. Personas con discapacidades. Cuidado. Capacidades.

\section{Introdução}

O problema da igualdade em sociedade recebeu tratamentos diversos de distintos campos do saber. No âmbito das ciências jurídicas, as questões de igualdade remetem tradicionalmente à análise das concepções de justiça. Bobbio entende que as noções de justiça e igualdade são intrinsecamente conectadas, na medida em que o "conceito e também o valor da igualdade mal se distinguem do conceito e do valor da justiça na maioria de suas acepções, tanto que a expressão liberdade e justiça é frequentemente utilizada como equivalente da expressão liberdade e igualdade" (BOBBIO, 1997, p. 14).

Bobbio se pauta pelos significados de justiça aristotélica ${ }^{1}$ para estabelecer que a relação entre igualdade e justiça se dá de forma condicional: para que se possa atribuir o qualitativo de "justo" a uma totalidade, é preciso que se preserve a instauração de uma certa

\footnotetext{
${ }^{1}$ Bobbio menciona especificamente a justiça como legalidade ("pelo o que se diz justa a ação realizada em conformidade com a lei") e a justiça como igualdade ("pelo o que se diz justa uma ação, justo um homem, justa uma lei que institui ou respeita, uma vez instituída, uma relação de igualdade") (1997, p. 20-21). Nesse sentido, conferir o livro V do "Ética à Nicômaco" (1996). A legalidade, a qualidade de estar conforme à lei, é atributo da ação do justo qualificado segundo uma concepção de justiça que é a de virtude completa. É no âmbito da justiça como virtude particular que a equidade se sobressai na justiça distributiva na já justiça corretiva.
} 
igualdade entre as partes - essa igualdade e o respeito à legalidade são aspectos condicionantes para o todo justo. Dessa forma, a noção de igualdade, em si mesma, não remete a um valor, mas somente o é na medida em que se consubstancia como condição necessária - ainda que não suficiente - para a verificação da ordem e da harmonia do todo dentro de um sistema cujo equilíbrio interno mereça o nome de justo. Em outras palavras, uma relação de igualdade é um desejo visado por condicionar o justo, na qual se entende que "justo" compreende uma ordem a instituir ou a restituir, respeitando-se as regras de que a cada um seja atribuído o que lhe cabe e de que tal equilíbrio seja mantido por regras universais. Que algo seja igual, portanto, nada significa se tal igual não conduz ao justo. Por este motivo, Bobbio entende como necessária a resolução das questões afetas à justiça anteriormente à qualificação do igual ou do desigual ${ }^{2}$. O que Bobbio chama de regra de justiça - implicada na noção de tratamento igualitário aos iguais e trato desigual aos desiguais - constitui-se posteriormente e em função do que é estruturado face à justiça como igualdade. Assim, a determinação do tratamento justo antecede à estipulação do tratamento igual, o que aprofunda as complexidades de definição do igual.

Noutro giro, Cuenca e Nussbaum afirmam que as teorias de justiça da tradição ocidental não têm sido atentas às demandas de alguns grupamentos historicamente minorados e discriminados (CUENCA, 2015, p. 35; 2016, p. 55) ${ }^{3}$. Nussbaum, especificamente, detecta como um dos problemas não solucionados pelas abordagens das teorias de justiça social ocidentais a questão da justiça para os indivíduos que chama de "pessoas com impedimentos físicos e mentais", que não foram até agora incluídos como cidadãos com base na igualdade em relação aos demais (NUSSBAUM, 2013, p. 2). Similarmente, Carlson e Kittay destacam

\footnotetext{
${ }^{2}$ Bobbio aponta a regra de justiça como aquela segundo "a qual se devem tratar os iguais de modo igual e os desiguais de modo desigual. (...) Com efeito, a regra de justiça pressupõe que já tenham sido resolvidos os problemas que pertencem à esfera da justiça retributiva e da justiça atributiva, ou seja, pressupõe que já tenham sido escolhidos os critérios para estabelecer quando duas coisas devem ser consideradas equivalentes e quando duas pessoas devem ser consideradas equiparáveis. Somente depois que estes critérios foram escolhidos é que a regra de justiça intervém para determinar que sejam tratados do mesmo modo os que se encontram na mesma categoria. Se não tivesse sido previamente estabelecido o modo como deva ser tratada essa ou aquela categoria, não teria nenhum sentido afirmar que os pertencentes à categoria devam ser tratados de modo igual”. (BOBBIO, 1997 , p. 20-21)

${ }^{3}$ No mesmo sentido, Nussbaum destaca a presença de pessoas com deficiências cognitivas severas como propositoras de um duplo desafio para as teorias de justiça. Assim descreve: "First, it poses a direct challenge. Here are some of our fellow citizens, and fellow participants in human dignity. Their needs, real and important, have not been adequately addressed by previous theories of justice. So the direct challenge asks us to design theories that address these needs and offer good normative guidance for societies seeking to do justice to them. Second, it poses an indirect challenge, by offering a test we can apply to all candidate theories of justice. We ask of each of the theories how the principles they suggest would treat the entitlements of people with cognitive disabilities, and we find fault with theories that, however attractive in other respects, cannot handle that issue well. By the same token, the ability of a theory to handle it well is at least one point in favor of such a theory. (NUSSBAUM, 2010, p. 75).
} 
que a filosofia política tem considerado a habilidade de raciocínio - e, mais restritamente, a racionalidade como atributo moral - como um marco do caractere da humanidade, sendo que fora para os dotados deste que as teorias têm estendido os mantos da igualdade, da dignidade, da justiça, da responsabilidade e da sociedade moral. Isto, em consideração a pessoas com deficiências intelectuais ou cognitivas - cuja habilidade de raciocínio, de acordo com um padrão de normalidade, pode apresentar-se diminuída sem que isto afete seu status de "pessoa" -, pode evidenciar o "cobertor curto" de conceitos como justiça, direitos, respeito, cuidado e responsabilidade (KITTAY, CARLSON, 2010, p. 1-2).

Nussbaum entende que, a despeito de existirem muitas perspectivas de justiça social na tradição ocidental, a ideia do contrato social - na qual há a reunião de indivíduos racionais, em um contexto de vantagens mútuas, com o fito de elaboração das regras primordiais de justiça pelas quais se governarão - tem sido uma das mais fortes, influenciando

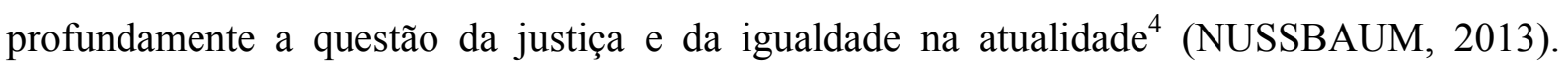
Kittay, do mesmo modo, aponta que a igualdade constitui um pilar sobre o qual teorias políticas de matriz liberal são erigidas, sendo o coração da teoria Rawlsiana, na qual a igualdade toma parte tanto na conceituação inicial de justiça - tarefa conduzida por pessoas moralmente iguais - quanto na aplicação dos princípios formulados - que conduz a uma organização social da qual resulta o igual gozo por todos de liberdades políticas e a justa distribuição econômica, com oportunidades iguais conferindo vantagens aos menos favorecidos (KITTAY, 1999, p. 78).

Nesse trabalho, em resposta à problemática mencionada, nosso objetivo consiste em analisar o conceito de justiça de Rawls no tocante à inclusão de pessoas com deficiência, tanto no momento da composição da justiça, no consenso hipotético da posição original, quanto no momento da aplicação das regras da justiça arquitetada. Primeiramente, delimitamos a deficiência como um dos problemas da justiça Rawlsiana, destacando a solução de adiamento de seu tratamento para o momento de funcionamento da justiça. São quatro, nesse momento, as clivagens da teoria de justiça rawlsiana que, a nosso ver, impedem o abrigamento da deficiência: o véu da ignorância cominado com a igualdade hipotética da posição original; o leque normal de variação; as desigualdades naturais consideradas no princípio da diferença; e

\footnotetext{
${ }^{4}$ Nesse sentido, Nussbaum: “A ideia do contrato feito no estado de natureza fornece, portanto, não somente uma explicação do conteúdo dos princípios políticos, mas, também, um marco referencial de legitimidade política. Qualquer sociedade cujos princípios básicos estivessem distantes daquilo que seriam escolhido por pessoas livres, iguais e independentes no estado de natureza seria posta em questão. Pelo fato de fornecer um modo claro, rigoroso e iluminador de pensar sobre a justiça entre as pessoas iguais, a tradição se manteve filosoficamente fértil. A teoria de justiça mais poderosa e influente do século XX, a de John Rawls, coloca-se diretamente dentro desta tradição" (NUSSBAUM, 2013, p. 3-14).
} 
a conceituação de "pessoas éticas" em Rawls. Em um segunda incursão, nos voltamos para as críticas performadas por Kittay, no âmbito da ética do cuidado e da interdependência, e de Nussbaum, no contexto da abordagem das capacidades. Para tanto, nos pautamos em uma metodologia de pesquisa hipotético-dedutiva, com abordagem qualitativo-descritiva e com aporte na revisão bibliográfica. A metodologia de pesquisa foi hipotético-dedutiva, com abordagem qualitativo-descritiva da revisão de literatura, considerando-se, como literatura primária, o referencial Rawlsiano e, como literatura secundária, as perspectivas críticas à teoria de Rawls delineadas por Nussbaum e Kittay.

\section{Uma Teoria da Justiça: colocando a deficiência entre os assuntos abordados por Rawls}

Rawls qualifica a justiça como "primeira virtude das instituições sociais" (1997, p. 3), sendo seu objeto primário a estrutura básica da sociedade, em face da qual as instituições sociais - dentre elas, as mais importantes seriam a Constituição política e os principais acordos econômicos e socais - operam a distribuição de direitos e deveres fundamentais (RAWLS, 1997, p. 7-8). Esta justiça - e seus princípios - seria fixada a partir de uma posição inicial de igualdade em que se encontrariam pessoas livres e racionais, preocupadas em promover seus próprios interesses, com vistas a definir os termos fundamentais de sua associação (RAWLS, 1997, p. 12). Nessa seção, fixamos conceitos essenciais da teoria de justiça Rawlsiana que fundamentam a exclusão epistemológica de pessoas com deficiência: a igualdade hipotética da posição original; o leque normal de variação; as desigualdades naturais aplainadas pelo princípio da diferença e o grau mínimo de capacidades para a dotação da personalidade ética.

\subsection{Igualdade hipotética na posição original: a ideia de um véu de ignorância}

A partir desta associação em uma situação de igualdade original - na qual às partes ${ }^{5}$ situadas atrás de um véu de ignorância ${ }^{6}$ é obstado o conhecimento de suas condições

\footnotetext{
${ }^{5}$ Um desenvolvimento desta noção na teoria de justiça Rawlsiana é percebido quando da análise da RAWLS, 1997, p. 561 e ss; 2000, p. 58 e ss; 2003, 26 e ss. Conforme aponta Nussbaum, a noção de "parte da posição original" é colocada de um "modo ligeiramente diferente” em Liberalismo Político (1996): “(...) as partes na posição original agora são vistas como 'representativas' ou fiduciárias dos cidadãos" (NUSSBAUM, 2013, p. 22). Importante, igualmente, artigo de 1992, no qual Rawls explicitamente se refere às partes como "os representantes de pessoas livres e iguais [que] devem especificar os termos da cooperação social no caso da estrutura básica da sociedade" (RAWLS, 1992).

${ }^{6}$ Kittay aponta que a função do véu da ignorância é assegurar que a escolha dos princípios de justiça não seja afetada pelo conhecimento de algum dos participantes da posição original sobre seu próprio lugar na sociedade; 
particulares $^{7}$ - seria possível derivar dois princípios de justiça em ordem serial ${ }^{8}$, quais sejam: cada pessoa deve ter um direito igual ao mais abrangente sistema de liberdades básicas iguais que seja compatível com um sistema semelhante de liberdades para as demais; as desigualdades sociais e econômicas devem ser ordenadas de tal modo que sejam, ao mesmo tempo, vantajosas para todos, dentro dos limites de razoabilidade, e vinculadas a posições e cargos acessíveis a todos (KITTAY, 1999, p. 65). O segundo princípio baseia-se na aplicação do chamado princípio da diferença, que norteia a existência de desigualdades econômicas e sociais, as quais "devem ser ordenadas de modo a serem ao mesmo tempo para o maior benefício esperado dos menos favorecidos e vinculadas a cargos e posições abertos a todos em condições de igualdade equitativa de oportunidades" (KITTAY, 199, p. 88).

Rawls estabelece a posição original ${ }^{9}$ tendo em mente a confecção "de princípios mais apropriados à realização da liberdade e da igualdade, considerada a sociedade como um sistema de cooperação entre pessoas livres e iguais" (RAWLS, 1992, p. 42). Partindo dessa teórica posição original, as partes devem estar simetricamente situadas para representar o papel de cidadãos livres e iguais em busca de condições equitativas. As características do sujeito da sociedade organizada equivalem, portanto, àquelas que credenciam um indivíduo para associar-se na composição dos princípios da justiça, correlacionando-se à existência de duas faculdades morais ou capacidades: capacidade de ter senso de justiça - compreendida como a que possibilita o entender da concepção pública de justiça característica dos termos equitativos da cooperação social, bem como sua aplicação e a ação a partir e de acordo com ela - e capacidade de formar uma concepção de bem - entendida como a que possibilita ter,

sobre sua própria visão de bem; e sobre suas próprias propensões, garantindo, assim, a imparcialidade e a razoabilidade na escolha dos princípios. As limitações da posição original refletiriam, portanto, termos adequados de cooperação social com os quais pessoas racionais poderiam concordar (KITTAY, 1999. p. 78-79).

${ }^{7}$ As partes dessa associação "não sabem como as várias alternativas irão afetar o seu caso particular, e são obrigadas a avaliar os princípios unicamente com base nas condições gerais" (KITTAY, 1999, p. 147).

${ }^{8} \mathrm{O}$ fato de essa derivação ajustar-se de forma serial garante a ausência de conflito entre referidos princípios, conforme bem explicita Barbosa-Fohrmann: "Esses princípios não entram em conflito, pois obedecem a uma ordem serial. O princípio da liberdade tem prevalência sobre o da igualdade e, portanto, não é limitado por ele. O princípio da liberdade só pode ser limitado, no momento de sua aplicação, por um outro princípio de liberdade. Disso se pode deduzir que as liberdades básicas, que compõem o rol do princípio da liberdade, não são absolutas em relação a outras liberdades básicas, mas são absolutas e têm prevalência sobre o rol de direitos provenientes do princípio da igualdade e da diferença" (BARBOSA-FOHRMANN, 2011, p. 46-47).

${ }^{9}$ A posição originária, em Rawls, é um artifício de representação, uma espécie de exercício que as pessoas livres e iguais devem fazer para chegar à concepção daquilo que teriam querido nos termos da concepção da justiça. Aponta o autor: "posição originária como um artifício de representação, isto é, essa posição modela o que tomamos como condições equitativas sob as quais os representantes de pessoas livres e iguais devem especificar os termos da cooperação social no caso da estrutura básica da sociedade, e como ela também modela o que, para esse caso, consideramos como restrições aceitáveis a respeito das razões disponíveis para as partes, pelas quais preferem um acordo e não outro, a concepção de justiça que as partes adotariam identifica a concepção que consideramos - aqui e agora - como equitativa e apoiada nas melhores razões" (RAWLS, 1992, p. 42). 
revisar e buscar atingir de modo racional uma concepção de bem ${ }^{10}$ (RAWLS, 1997. p. 56061; 2003. p. 26-34). A presunção de igualdade original fornece a homogeneidade necessária para que as partes reconheçam a legitimidade umas das outras como consideram a sua própria (SILVERS; FRANCIS, 2005, p. 45). Contudo, por causa da igualdade hipotética condicionada à posse de poderes morais, esses partidos "ignoram qual será seu gênero, raça ou classe social, mas sabem com certeza que não serão pessoas com deficiências graves" (CUENCA, 2015, p. 37).

Nesse ponto, uma importante ressalva a se fazer é a de que é possível que a ausência das pessoas com deficiência seja intencionalmente visada na posição de Rawls, e que essa seja uma limitação de sua teoria - a qual Rawls não deixa de admitir. Nesse sentido, Rawls argumenta em Liberalismo Político que sua "ideia de justiça política não abrange todas as coisas, nem é de se esperar que o faça” (2000, p. 64). Isso porque ou o problema não enfocado não é, de fato, um problema de justiça política segundo a concepção da justiça como equidade ou por que falte-lhe, enquanto propositor dessa teoria, "perspicácia" para sugerir como deve se estender o conceito. Seja como for, Rawls entende que não se deve "esperar que a justiça como equidade, ou qualquer concepção de justiça, abranja todos os casos de certo e errado. A justiça política sempre precisa ser complementada por outras virtudes” (2000, p. 64).

\subsection{Pessoas com deficiências fora do "leque normal de variação"}

A ideia primordial, aponta o autor, é que a liberdade qualifica as pessoas que possuem essas duas faculdades morais e as faculdades da razão - de julgamento, pensamento e inferência, ligados às primeiras. A partir dessa detenção em um grau mínimo, as partes são consideradas como plenamente cooperativas da sociedade e entendidas como dotadas de igualdade (RAWLS, 200, p. 61-62). Há, pois, uma simetria das partes representantes da sociedade justa em via de se estabelecer enquanto tal, partindo-se unicamente do pressuposto que o grau mínimo necessário das faculdades supracitadas as credencia dentro de um "leque normal de variação" (RAWLS, 2000, p. 68), cujas nuances não podem ser desveladas em face da ignorância.

\footnotetext{
10 Cuenca aponta que "para Rawls la capacidad para un sentido de la justicia significa razonabilidad, comprensión como habilidad de relacionarse con otros e iguales ciudadanos y para participar con otros en términos que podemos imaginar que otros aceptarían, mientras que la capacidad para una concepción del bien implica que las personas son racionales para determinar sus propias metas, esto es, sus propios planes y proyectos de vida y para tomar los pasos más apropiados para conseguirlas" (CUENCA, 2012. p. 107).
} 
Esta equivalência dentro de um leque normal de variação permite o estabelecimento de termos equitativos de cooperação, implicando uma ideia de reciprocidade; ou seja, todos os que estão envolvidos na cooperação devem beneficiar-se da forma apropriada (RAWLS, 2000, p; 59). A definição do leque normal de variação, feita em nota de rodapé do Liberalismo Político, é bastante esclarecedora quanto à não inclusão das pessoas com deficiência na ideia de pessoa moral, tanto na concepção quanto na aplicação da teoria. $\mathrm{O}$ autor compreende que, uma vez que o problema fundamental da justiça diz respeito às relações entre aqueles que participam plena e ativamente da sociedade e que se associam ao longo de sua vida, é razoável supor que todos têm as necessidades físicas e capacidades psicológicas dentro de um leque normal de variação ${ }^{11}$. Como ele afirma: "o problema de tratamentos médicos especiais e de como cuidar dos deficientes mentais é posto de lado. Se pudermos elaborar uma teoria viável para o leque normal, podemos tentar, depois, resolver esses outros casos" (RAWLS, 2000, p. 325). Ou seja: em Rawls, não é um problema fundamental de justiça promover a participação plena daqueles que não possuem as faculdades morais citadas. Problema fundamental de justiça é, portanto, resolver a questão da relação entre os "normais", postergando a questão dos "anormais" (KITTAY, 1999, p. 80).

Em Liberalismo Político, Rawls fixa quatro tipos de variações, que qualificam as pessoas abaixo ou acima de uma "linha divisória", cujo sobrepujo corresponde ao logro das capacidades essenciais mínimas para ser um membro cooperativo normal da sociedade. São elas: variações nas capacidades e habilidades morais e intelectuais; variações nas capacidades e habilidades físicas; variações nas concepções de bem; variações nos gostos e preferências. Ao tratar das duas primeiras, Rawls admite que as únicas variações de capacidades morais, intelectuais e físicas consideradas são aquelas qualificadas acima do mínimo essencial, sendo a etapa legislativa o momento apropriado para resolver as questões atinentes às pessoas cujos

\footnotetext{
${ }^{11}$ Em defesa de Rawls, Barbosa-Fohrmann aponta uma interpretação segundo a qual todos e todas potencialmente são pessoas morais e cooperativas: "Podemos, ainda assim, intentar uma defesa do pensamento de Rawls nesse particular, fazendo um liame com o que foi anteriormente sugerido sobre a possibilidade de todos os indivíduos se tornarem potencialmente pessoas morais por possuírem um sentido basilar de justiça. Em sociedade, poderia se assumir ainda que todos podem se tornar potencialmente cidadãos por meio de uma interpretação do significado de full social cooperation" (BARBOSA-FOHRMANN, 2013, p. 85). A sugestão da potencialidade é anteriormente feita, de forma mais aprofundada, em Wong (2009), que antecipa, ainda, as duas críticas possivelmente feitas a essa visão: em primeiro lugar, as dificuldades epistêmicas, baseadas na imprevisibilidade tanto de quais serão as pessoas aptas a desenvolver as faculdades morais quanto nas condições empoderadoras que serão necessárias para esse desenvolvimento; em segundo lugar, a autora considera o argumento dos casos marginais, que coloca a questão da superinclusão de outras espécies de animais nãohumanos no âmbito da justiça. Nos limitamos, aqui, a expor o argumento da potencialidade, sem entrar no pressuposto que resguarda de naturalidade das desigualdades. É dizer: se há pessoas que realizam as condições para a qualificação como pessoa ética e outras apenas as detém em potencialidade - sendo que apenas a potencialidade nos interessa para que sejam sujeitos de justiça -, ainda assim, careceríamos de uma visão forte de desigualdade natural e imerecida, que, se não elimina, certamente dilui a importância do conceito de barreiras para a geração de desigualdades.
} 
caracteres localizam-nas abaixo de sobredita linha de capacidades, momento no qual "a ocorrência desses infortúnios e seus tipos é conhecida e os cursos de seu tratamento podem ser verificados e computados nos gastos totais do governo" (2000, p. 231-232).

Por este raciocínio, Rawls estabelece um padrão mínimo de caracteres que as partes da posição original devem possuir, estabelecendo, pois, um critério individual capacitista ${ }^{12}$. Ao estabelecer tais parâmetros, o autor exclui aqueles que não possuem tal grau mínimo de faculdades exigidas na configuração de uma personalidade ética, de sorte que estes não podem ser partes da concepção da justiça, experenciando-a apenas como entidades dependentes (SILVER; FRANCIS, 2009, P. 476). Esta situação poderia configurar-se no caso de pessoas com diversas deficiências, cujas condições intelectuais, mentais e físicas ${ }^{13}$ desqualifiquem mencionado grau mínimo necessário de faculdades. Em uma analogia precária, podemos supor que, caso a posição primordial equiparasse-se a uma peça teatral, as pessoas com deficiência jamais poderiam interpretar papéis de atuação determinantes no enredo, qualificando-se como personagens apenas derivativamente (NUSSBAUM, 2013, p. 189), por menção ou por extensão. Essa sua articulação jamais estaria apta a alterar $a$ narrativa das negociações na posição original, que invariavelmente conduziriam aos princípios desenhados para as pessoas livres e iguais representadas.

É possível, pois, afirmar que, por mais que as partes da posição original de Rawls não saibam de suas próprias qualificações ou das qualificações daqueles que representam, elas sabem que possuem, pelo menos, um grau mínimo do considerado necessário nos termos das faculdades morais e racionais aportadas, não estando em incapacidade permanente ${ }^{14}$. O véu da ignorância não considera portanto, as pessoas com deficiência que deverão confiar naquelas

\footnotetext{
12 Apesar de admitir que os cidadãos têm diferentes capacidades, Rawls aduz que, para serem consideradas as pessoas dotadas de personalidade ética, as partes precisam ter um grau mínimo essencial de faculdades morais, intelectuais e físicas que lhes possibilitam ser plenamente cooperativas ao longo de toda a vida. (RALWS, 2000. p. 230). Nussbaum aponta que esta ênfase em capacidades correlacionadas à cooperação advém do contratualismo, que fundamenta a ideia de que as pessoas só se reúnem e estabelecem por contrato os princípios políticos básicos em certas circunstâncias, a partir das quais seja possível obter vantagens mútuas; incluir, portanto, pessoas que contribuem menos do que um grau mínimo necessário de capacidades está apto a contribuir ou que têm demandas mais onerosas atenta a lógica contratual (NUSSBAUM, 2013 p. 130).

${ }^{13}$ Nussbaum entende que Rawls posterga a um estado posterior de natureza legislativa a regulamentação das necessidades de pessoas cegas, surdas, cadeirantes, com doenças mentais graves (incluindo depressão grave) e pessoas com graves impedimentos cognitivos e outros impedimentos de desenvolvimento (NUSSBAUM, 2013, p. 139-140).

${ }^{14}$ Para Cuenca: "Desde estos referentes, las personas con discapacidad no son consideradas en la construcción rawlsiana sujetos primarios de justicia. Los individuos que tratan de llegar a un acuerdo en la posición original acerca de los principios políticos básicos ignoran cuál será su género, su raza, o su clase social, pero saben a ciencia cierta que no serán personas con graves discapacidades. (...) Las personas con discapacidad son tratadas como 'ciudadanos de segunda', tanto por lo que respecta a su consentimiento, como por lo que respecta a sus demandas e intereses. En definitiva, la teoría rawlsiana no puede hacer justicia con las personas con discapacidad y las excluye directamente del debate moral" (CUENCA, 2012, p. 107-108). 
que delas não são representativas ou fiduciárias para que concebam uma noção de sociedade que seja justa o suficiente para também - e por reverbero - atendê-las. Ademais, se entre as partes da posição original persiste a certeza de que nenhuma destas ou dos representados qualifica-se como incapaz, possuindo todos um grau mínimo de talentos e condições físicas e intelectuais, nada garante que elegerão uma estrutura de justiça básica que considere a inclusão das pessoas com deficiência em igualdade de condições com os demais. Há um empecilho nas condições de alteridade que poderiam conduzir a estruturas inclusivas, uma vez cientes de que, independentemente do que ou de quem representem, jamais representarão pessoas com deficiências e seus interesses.

Por outro lado, mesmo quando se considera razoável a ideia da linha das capacidades - coerentes com uma cooperação produtiva socialmente, fundamentando a reciprocidade contratual -, cumpre que se denote a impossibilidade de se trasladar do lado de baixo da linha - no qual o malogro do grau mínimo obsta a condição de parte - para o lado de cima. Isto porque mesmo quando consideramos aquelas pessoas com deficiência que pudessem aportar à sociedade tanto quanto os demais, condicionado tal aporte unicamente a determinadas alterações contextuais, teríamos que admitir que essas teriam poucas chances de fazê-lo em uma sociedade pensada entre os integrantes qualificados acima da linha, dado que aqueles não tiveram que "legislar" princípios de justiça representantes dos interesses dos integrantes abaixo da linha. Apenas em uma fase legislativa posterior à estruturação da justiça, em pleno funcionamento das estruturas básicas daí advindas, poderá a pessoa com deficiência representar-se. Ainda assim, esta percepção ganha contornos complicados ao se considerar que os instrumentos de participação e engajamento social e político foram igualmente pensados por partes que, necessariamente, não possuem deficiência.

\subsection{Desigualdades naturais e a desconsideração das barreiras sociais}

Em Liberalismo Político, Rawls aponta a deficiência como um dos quatro problemas de sua teoria - ao lado das questões dos deveres para com as gerações futuras, de direito das gentes, dos direitos dos animais e da natureza. O autor, ao entender a concepção de justiça em uma sociedade equitativa e cooperativa, formada por cidadãos livres, iguais e normais, como a questão fundamental da justiça política, aponta que acidentes ou doenças - ao que tudo indica, em grau incapacitante quanto às faculdades morais que prevê - são desgraças ${ }^{15}$

\footnotetext{
${ }^{15}$ Importante destacar que apesar de não se referir especificamente às pessoas com deficiência, Rawls parece ter estas em mente quando fala se refere a pessoas que sofrem acidentes ou doenças como frutos das "desgraças" 
ocorridas durante o curso normal da vida, "eventualidades" em face das quais a tomada de providências é necessária. Rawls reconhece, portanto, como problemática a questão dos que não satisfazem - temporária ou permanentemente - as capacidades necessárias para assumir o papel de "membros normais e plenamente cooperativos da sociedade ao longo de toda a vida”. Face a este reconhecimento, o autor aloca a resposta para esta questão no provimento de um "atendimento médico normal", ressalvando, no mais, que a ideia de justiça política não abrangerá todas as situações. Rawls adia, portanto, a questão da deficiência para um estágio legislativo de funcionamento das engrenagens da justiça pensada sob a posição original (RAWLS, 2000, p. 63-64).

Postula o autor que a concepção igual de justiça - entendida a partir do segundo princípio de justiça, que engloba o princípio da igualdade equitativa de oportunidades e o princípio da diferença (RAWLS, 1997, p. 79) - alberga a noção de reparação das desigualdades imerecidas, mencionando especificamente as desigualdades "de nascimento e de dotes naturais", as quais por não serem merecidas, devem ser compensadas. Rawls aponta que desigualdades inatas devem ser aplainadas. O trato de uma pessoa com deficiência intelectual cujo nascimento é encarado como um fato natural, por exemplo, deve ser alocado no campo do "desvio das contingências em direção da igualdade". Nesse sentido, Rawls chega a mencionar que mais recursos devem ser gastos na educação dos "menos inteligentes" (1997, p. 107), considerando, assim, a inteligência como um dote natural.

Essa percepção entende a deficiência como um conceito desprovido do dinamismo conceitual da Convenção de Direitos das Pessoas com Deficiência (CDPD) ${ }^{16}$. Podemos considerar que essa perspectiva de "desigualdades naturais" constitui uma negação dos modelos de deficiência social e de direitos humanos, visto que pessoas com "prejuízos imerecidos", localizadas abaixo da "faixa normal", ganharam vida em uma sociedade

normais do ciclo da vida. Esta passagem reflete, com clareza, o reflexo, na teoria de justiça de Rawls, da "teoria da tragédia pessoal da deficiência" descrita Swain e French, que a conceituam nestes termos: "In the personal tragedy theory, disability, or rather impairment which is equated with disability, is thought to strike individuals causing suffering and blighting lives. (...) Perhaps the most intrusive, violating and invalidating experiences, for disabled people, emanate from the policies, practices and intervention which are justified and rationalised by the personal tragedy view of disability and impairment. The tragedy is to be avoided, eradicated or 'normalised' by all possible means" (SWAIN; FRENCH, 2004).

${ }^{16}$ Cf. Art. 1 da CDPD, que define pessoas com deficiência como "aquelas que têm impedimentos de longo prazo de natureza física, mental, intelectual ou sensorial, os quais, em interação com diversas barreiras, podem obstruir sua participação plena e efetiva na sociedade em igualdades de condições com as demais pessoas". A CDPD foi aprovada em 13 de dezembro de 2006, entrando em vigor em 3 de maio de 2008, depois de sua vigésima ratificação. O Brasil figurou, em 30 de março de 2007, como parte signatária deste tratado multilateral, incorporando-o ao ordenamento jurídico interno em consonância com o art. $5^{\circ}, \S 3^{\circ}$, da $\mathrm{CF} / 88$, por meio do Decreto Legislativo $\mathrm{N}^{\mathrm{o}} 186$, de 9 de julho de 2008. O texto é, portanto, o primeiro tratado de Direitos Humanos com status formal constitucional. Posteriormente, em 25 de agosto de 2009, pautado no previsto no art. 84, IV, da Constituição, o Presidente da República sancionou o documento por meio do Decreto Presidencial No 6.949 para dar execução, em nível interno, ao texto convencional. 
projetada por representantes daqueles localizados acima da linha. Portanto, a concepção de compensação de desigualdade de Rawls oblitera a consideração das barreiras que impedem a participação plena e efetiva das pessoas com deficiência em igualdade de condições com as demais pessoas, sem deficiência. Além disso, tanto o "alcance normal", que denota o grau mínimo securitizado pelos partidos reciprocamente cooperativos, quanto a própria concepção de personalidade moral, podem ser considerados como impeditivos estruturais da igualdade entre pessoas com deficiência e demais pessoas, sem deficiência.

Evidencia-se, pois, uma incongruência entre o modelo de direitos humanos ${ }^{17}$ e a aplicação do segundo princípio de Rawls, uma vez que sua concepção de reparação do desvio oblitera as barreiras do meio enquanto fatores determinantes para as disparidades de gozo de igualdade de oportunidades entre as pessoas com deficiência e os demais. Nesse sentido, ao constatar um "menor favorecimento" de um estudante em relação aos demais, o autor aponta, como solução, uma maior alocação de recursos na educação, com vistas a melhorar suas expectativas a longo prazo (1997, p. 107-108); sua concepção, neste sentir, em muito se alinha aos auspícios da integração escolar, que não demanda qualquer alteração do meio de ensino - mas sim do estudante com deficiência e de suas expectativas, a partir do aprimoramento de suas habilidades em direção a um parâmetro pré-determinado de normalidade ${ }^{18}$.

A principal crítica da inclusão à esse tipo de concepção é o de que o mero investimento em recursos que se consideram apropriados para um tipo específico de desenvolvimento estudantil (i.e., o do estudante normal ou médio), sem repensar-se as demandas específicas e individualizadas de cada estudante, tenderão para a assimilação. Dessa forma, maior investimento não significa mais respeito à diversidade. Considere, por exemplo, o caso de políticas educacionais que valorizam a aquisição de livros escolares, sem considerar a necessidade de materiais específicos que respeitem a acessibilidade informacional e literária, tendo em vista, por exemplo, materiais de leitura fácil, materiais acessíveis a leitores de tela, materiais em braile, dentre outros.

Do ponto de vista da CDPD, o meio e as barreiras nele contidas constituem-se enquanto fatores essenciais no entendimento das desigualdades correlacionadas à situação de deficiência $^{19}$. A percepção Rawlsiana entende a deficiência como um conceito desprovido da

\footnotetext{
${ }^{17}$ Para uma definição do modelo de direitos humanos, Cf. DEGENER, 2016.

${ }_{18}^{18}$ Para conferir as diferenças entre integração e inclusão, V. BARBOSA-FOHRMANN et al, 2014.

${ }^{19}$ Destaque-se a dupla discordância com o consagrado por Vita, ao entender que "é comum o adepto de posições políticas de esquerda dar uma ênfase maior aos fatores ambientais que condicionam o desempenho de cada cidadão na vida política, econômica e social, ao passo que o direitista típico gosta de enfatizar a capacidade 
dinamicidade convencional, configurado enquanto um dado em si a partir do nascimento ou do acidente - reforçando-se ainda mais a teoria da tragédia pessoal. A investigação se torna ainda mais complexa se se considera que essas pessoas com impedimentos imerecidos, localizadas abaixo da linha das capacidades, vieram à luz em uma sociedade pensada sob os auspícios das negociações empreendidas supostamente por representantes daqueles localizados acima da linha das capacidades. Parece razoável concluir que esta sociedade não estará pensada, portanto, para as pessoas com deficiência, sendo permeada por barreiras sociais, jurídicas, políticas e estruturais. Ainda, tanto a linha das capacidades, que denota o grau mínimo titularizado pelas partes reciprocamente cooperativas, quanto a própria concepção de personalidade moral pode ser considerada como uma barreira política à igualdade de condições e oportunidades.

\subsection{Seriam as pessoas com deficiência "pessoas éticas" para Rawls?}

Por fim, em Uma Teoria de Justiça, ao abordar as "características dos seres humanos em virtude das quais eles devem ser tratados de acordo com os princípios da justiça" (1997, p. 560), Rawls alcunha tais atores de "pessoas éticas", entendendo as personalidades éticas potenciais nestas contidas como condição suficiente para que tenham direito à justiça igual. Em outras palavras, a justiça igual é um direito daqueles que têm a capacidade de participar da situação inicial e de agir de acordo com o entendimento comum ${ }^{20}$. Neste ponto, os dois arquétipos que fornecem as características dos sujeitos que se articulam no bojo da teoria Rawlsiana - qual seja aquele pensado ao início, na concepção da justiça, e aquele estruturado

genética herdada. Esta é a cidadela última para onde os políticos e economistas conservadores recuam quando querem justificar as desigualdades sociais existentes. Rawls sugere uma outra estratégia argumentativa para criticar essas desigualdades: importa pouco determinar qual desses dois fatores pesa mais para gerá-las; na prática, é impossível dissociar um do outro e ambos são igualmente arbitrários de um ponto de vista moral" (VITA, 1999). Entende-se aqui que a desigualdade das pessoas com deficiência é endossada tanto no começo estruturação da justiça - como na aplicação - funcionamento das estruturas básicas - de sua teoria, uma vez que a pessoa com deficiência resta alijada da primeira justamente por motivos, em geral, exclusivamente genéticos (associados a ideia de talentos e habilidades naturais) bem como é menoscaba no contexto da segunda etapa, na medida em que as barreiras ambientais e atitudinais deverão ser combatidas em uma sociedade que não pensou o meio como fator intrínseco à desigualdade. Todas estas questões advém de um entendimento individualista da deficiência, que aloca sua ocorrência no campo da desgraça ou do infortúnio arbitrário.

${ }^{20} \mathrm{O}$ autor distingue três níveis em que o conceito de igualdade se aplica. O primeiro refere-se à administração das instituições como sistemas públicos de regras, sendo, neste caso, a regularidade da justiça a consubstanciação da igualdade. No segundo nível, Rawls correlaciona a noção de igualdade a estrutura substantiva das instituições, sendo então o seu significado especificado pelos princípios da justiça que comandam a distribuição de direitos básicos iguais a todas as pessoas. Neste ponto, é importante destacar que, para Rawls, os animais estão excluídos da distribuição, na medida em que não se enquadram no padrão de seres para os quais se deve conceder as garantias de justiça. A terceira camada corresponde justamente à definição de quem é titular do direito à justiça igual, sendo então aqueles que têm capacidade de participar da situação inicial e de agir de acordo com o respectivo entendimento comum (1997, p. 560-561). 
ao final, na aplicação dos princípios de justiça - se sobrepõem, de forma que todo aquele que pode participar da situação inicial pode também ter direito à justiça igual.

A personalidade ética derivada da potencial satisfação das capacidades, aponta Rawls, é sempre satisfeita no seu devido tempo, sendo sempre suprida enquanto condição de garantias de direitos. Aduz o autor que considerar tal condicionamento em uma sociedade idealmente justa é razoável, na medida em que, mesmo que a capacidade não existisse, seria insensato, na prática, negar direitos com base nisso em tal sociedade inteiramente justa (1997, p. 561-562). Isto significa dizer que a sociedade justa idealizada pelos participantes capazes da posição original seria tão justa que não poderia gerar uma negação de direitos com base na falta de capacidade para participar da posição original. Assim, na acepção de Rawls, as pessoas com deficiência, por mais que não possuíssem as faculdades morais exigidas para tomar parte na situação inicial e por mais que não se tivessem estas em mente quando se projetou os princípios da justiça - considerando uma sociedade de pessoas livres e iguais, reciprocamente cooperativas - , seriam albergadas pela justiça unicamente porque a sociedade é justa a este ponto.

Portanto, há, em princípio, dois aspectos de consideração da noção de igualdade em Rawls ao tratarmos da deficiência: o estado da posição inicial, pautado na igualdade das partes representativas da teoria de justiça, e o segundo princípio de justiça, baseado nos princípios da igualdade equitativa de oportunidades e no princípio da diferença. Ante ao analisado, deve-se destacar dois desafios estruturados em virtude da deficiência: a exclusão das pessoas com deficiência da composição inicial de justiça e a noção individualista da desigualdade de oportunidades ensejada pela situação de deficiência em sociedade. Tais desafios restam denotados por uma percepção de deficiência cujo enfoque é restrito às limitações que a deficiência conjuga em face de um padrão de normalidade de capacidades predeterminado.

\section{Com Rawls, contra Rawls: Nussbaum e Kittay em busca de alternativas teóricas}

O entendimento de que as teorias de contrato social de matriz Rawlsiana não podem fazer justiça às pessoas com deficiência conduziu à estruturação de teorias pensadas especificamente em resposta a esta inadequação. A este teor, Eva Kittay e Martha Nussbaum desenvolveram, respectivamente, ideias de justiça a partir da ética do cuidado e do enfoque das capacidades. Enquanto a primeira filósofa tece sua teoria a partir da crítica da dependência à igualdade - o que conduz à ideia de interdependência pela igualdade ou, 
reciprocamente, igualdade pela interdependência ${ }^{21}$ - a segunda estrutura seu arcabouço teórico a partir de uma substituição da ênfase no contrato procedimental para a ênfase na justiça substancial com objetivos distributivos . Nesta seção, analisamos as consequências de referidos quadros referenciais para a formação de uma concepção de justiça inclusiva de pessoas com deficiência.

3.1 O enfoque das capacidades de Martha Nussbaum

Nussbaum aponta que o enfoque das capacidades é o adequado para tratar a questão da deficiência dentro da justiça, sendo esta abordagem apta a exigir que os governos respeitem e implementem garantias humanas centrais, identificadas em uma lista de capacidades. Para a autora, essas capacidades estão no núcleo do conceito de vida humana digna, existindo um nível mínimo para cada capacidade, abaixo do qual considera como inexistente as condições de possibilidade para um funcionamento verdadeiramente humano (NUSSBAUM, 2013, p. 83-85). Nussbaum parte dessa ideia para estabelecer uma lista de dez capacidades vitais como exigências centrais para uma vida digna, estabelecendo um rol de requisitos mínimos de garantias para a consecução destas capacidades, sem o adimplemento dos quais uma sociedade não pode ser considerada completamente justa. Tais capacidades são: vida; saúde física; integridade física; sentidos, imaginação e pensamento; emoções; razão prática; afiliação; outras espécies; controle sobre o próprio ambiente (NUSSBAUM, 2013, p. 90-93).

Cuenca entende que a teoria de Nussbaum, em que pese promissora para as pessoas com deficiência, pode mostrar-se menos inclusiva do que declara, sobretudo para algumas pessoas com deficiências específicas (CUENCA, 2012, p. 109-111). Do mesmo modo, Barbosa-Fohrmann entende que a inclusão do discurso de Nussbaum "abrange as pessoas com múltiplas formas de deficiências graves, mas não as extremas ou profundas que impeçam a pessoa de estabelecer qualquer vínculo com o meio familiar e social" (BARBOSAFOHRMANN, 2017, p. 751). Este também é o entendimento de Stein ao apontar que o

\footnotetext{
${ }^{21}$ Kittay parece não objetivar construir uma nova teoria de justiça, conforme aponta a autora: "My claim is that those within relations of dependecy fall outside the conceptual perimeters of Rawls's egalitarianism. (...) I argue that the two principles of justice cannot accommodate the objections of dependency critique unless Rawls's foundational assumptions are altered. In pointing to omissions in this theory, I contemplate ways in which the Rawlsian position could be amended. Wheather the suggestions put forward suffice to make the theory amenable to dependency concerns without introducing new incoherencies for the theory is a question I leave for Rawlsians. My aim is neither to reform Rawls's political theory, nor to say that it cannot be reformed. Rather, I offer arguments of dependency critique as criterion of adequacy, one applicable to any political theory claiming to be egalitarian" (KITTAY, 1999. p. 79). 
enfoque das capacidades não é suficiente para empoderar as pessoas com deficiência no que diz respeito a seu direito de estar no mundo. Para o autor, o esquema de Nussbaum falha ao reconhecer a dignidade plena como predicado apenas daqueles cujos funcionamentos ocorrem acima do considerado mínimo (STEIN, 2007, p. 101-102). Neste sentido, a consideração das capacidades centrais como elementos estritamente determinantes de uma vida com dignidade pode conduzir a qualificação como menos dignos dos sujeitos que não as possuem.

Por este motivo, Silvers e Francis afirmam que fixar parâmetros mínimos de capacidade pode conduzir a opressões, derivadas, primeiramente, da identificação dos que jamais atingiram estes padrões, os anormais, que poderão vir a ser estigmatizados, e, segundamente, da noção de retribuição aos recursos alocados para a aquisição do grau mínimo de capacidades, que eventualmente gera a assimilação de pessoas que não podem ser assimiladas ou para quem a assimilação é extremamente dolorosa (SILVERS, FRANCIS, 2005, p. 54-55). Tais advertências parecem se concretizar na passagem em que Nussbaum, ao falar de sua percepção acerca da vida de $\mathrm{Sesha}^{22}$, entende que o não alcance das capacidades centrais por parte desta é um evento extremamente lastimável, uma vez que, quando alguém não as alcança, essa é uma ocorrência naturalmente infeliz. Nussbaum entende que as capacidades constantes em sua lista são realmente importantes e boas e que não ter aptidão para atingi-las é uma tragédia - lembrando a concepção da já citada teoria da tragédia pessoal.

Mais interessante ainda é seu entendimento de que, se fosse possível curar Sesha de forma a trazê-la para um nível mínimo de capacidades, isto seria feito em face de seu enfoque das capacidades. A autora toca, ademais, no ponto crucial da eugenia tão amplamente

\footnotetext{
${ }^{22}$ Sesha é fillha de Eva Kittay, tendo motivado pessoalmente as teorias desta. Para entender as diferenças de perspectiva de Kittay e Nussbaum, é importante cotejar as palavras com as quais as duas a descrevem. Nussbaum fala: "Sesha (...) é uma jovem mulher de vinte e tantos anos. Cativante e carinhosa, ama música e vestidos bonitos. Responde com alegria ao afeto e admiração dos outros. Sesha balança ao ritmo da música e abraça seus pais. Mas jamais poderá andar, falar ou ler. Por causa de uma paralisia cerebral congênita e retardo mental grave, será sempre profundamente dependente dos outros. Precisa ser vestida, lavada, alimentada e que a levem para passear pelo Central Park em cadeira de rodas." E depois: "Considerando tudo isso, ela tem portanto, uma expectativa pequena de desfrutar o gozo espontâneo da sexualidade e da criação de filhos, e talvez nenhuma perspectiva de uma vida com atividade política significativa, iniciada por ela própria. (...) Assim, o que temos claramente de dizer, me parece, é que algumas das capacidades na lista não serão atingíveis por ela, mas que isso é extremamente lastimável, não um sinal de que ela esteja florescendo em uma forma diferente de vida" (NUSSBAUM, 2013. p. 117, 236). A descrição de Kittay, por outro lado, conjuga de uma perspectiva diversa: "How to speak of it? How to describe it? Joy. The capacity for joy. The babbling-brook laughter at musical joke. The starry-eyed far away look as she listens to Elvis crooning 'Love Me Tender', the excitement of her entire soul as the voices blare out 'Alle Menschen weder Brüder' in the choral ode of Beethoven's Ninth Symphony, and the pleasure of bestowing her kisses and receiving the caresses in turn. All variations and gradations of joy. Spinoza characterized joy as the increase in our power of self-preservation and by that standard, Sesha's is a very well-preserved self. Yet she is so limited. She cannot speak. She cannot even say 'Mama' - though sometimes we think she says 'Aylu' (our translation, 'I love you') (...) Given the scope and breadth of human possibilities and capacities, she occupies a limited spectrum, but she inhabits it fully because she hast the most important faculties of all. The capacities for love and for happiness" (KITTAY, 1999, p. 151-152).
} 
rechaçada pela crítica expressivista ${ }^{23}$, entendendo que "se pudéssemos interferir nos seus aspectos genéticos já no útero, de modo que ela não nascesse com impedimentos tão graves, então, de novo, isso seria o que uma sociedade digna deveria fazer" (NUSSBAUM, 2013, p. 236-238). Esta postura diferencia-se integralmente da ideia de prevenção albergada pelo modelo de direitos humanos, dado que a prevenção qualifica-se como um trabalho que não se pauta em mensagens negativas acerca da deficiência ${ }^{24}$. Por esta perspectiva, a teoria de Nussbaum é insuficiente, por não ser inclusiva em relação a determinadas deficiências, abrindo margem para que as pessoas que as detêm sejam caracterizadas como desprovidas de dignidade e incompetentes na realização das capacidades básicas.

\subsection{Kittay: igualdade e dependência por meio do cuidado}

Kittay, por outro lado, propõe o que chama de crítica da dependência à igualdade Rawlsiana, evidenciando a negligência dos assuntos de dependência e as consequências desta omissão em teorias que buscam abordar a igualdade e a justiça social. Para tanto, a autora elucida inicialmente cinco pressuposições que afirma estarem no plano de fundo do conceito de igualdade em Rawls, argumentando que teorias de justiça que as ignorem manterão a estruturação de princípios inaptos a responder às objeções da crítica da dependência (KITTAY, 1999, p. 76-79). Inicialmente, cumpre sublinhar que a dependência, em Kittay, nada mais é do que um aspecto natural da vida humana, que não surge somente em circunstância excepcionais, sendo chamado de "trabalho de dependência" o realizado pelos que atendem às demandas dos dependentes ${ }^{25}$.

\footnotetext{
${ }^{23}$ Para uma elaboração teórica sobre a crítica expressivista da deficiência, Cf. DINIZ, 2003.

${ }^{24}$ Veja-se que Shakespeare cita o exemplo do trabalho de prevenção na paralisia cerebral, a qual é pode ser gerada por partos prematuros e complicações durante o parto. Os cuidados durante a gestação no sentido de reduzir a incidência de paralisia cerebral não expressam uma mensagem negativa acerca da qualidade de vida ou das capacidades das pessoas com paralisia cerebral. Já a ideia de que seria melhor corrigir seus impedimentos com intervenções no estágio uterino conduz a noção de que é melhor corrigir a deficiência do que arcar com a tragédia de se viver uma vida com paralisia cerebral (SHAKESPEARE, 2014. p. 120).

${ }^{25}$ Neste ponto, é importante ressaltar o papel de destaque que a autora dá para a construção de um paradigma de cuidador ou trabalhador de dependência que considera cuidado, preocupação e conexão como postulados. Clarifica, contudo, algumas ressalvas. Primeiramente, a noção de interdependência, na qual há o cuidado simultâneo e recíproco, que pode ocorrer quando uma das partes em uma relação não está profundamente impedida ou está diferentemente posicionada em relação à outra parte. Em segundo lugar, o trabalho de dependência não precisa estar no encargo de uma só pessoa, uma vez que a justa distribuição desse trabalho é central para a sua crítica. Em terceiro lugar, o fato de existirem cuidadores que tem o desenrolar de seu trabalho como uma profissão, qualificando-os dentro de uma classe laboral, não dirime as questões distributivas que demandam o compartilhamento do trabalho de dependência (KITTAY, 1999. p. 29-32).
} 
A primeira das cinco pressuposições contestadas por Kittay diz respeito às circunstâncias de justiça Rawlsianas, tanto objetivas quanto subjetivas ${ }^{26}$, que ignoram as necessidades da dependência nas questões distributivas concernentes à escassez moderada de recursos. Kittay aponta que, na posição original de Ralws, as partes representativas são incapazes de resolver problemas derivados da dependência. Isto porque elas estariam representando uma linha contínua geracional, em virtude do que Rawls as qualifica como "chefes de família que têm, portanto, um desejo de promover pelo menos o bem-estar de seus descendentes mais próximos" (RAWLS, 1997, p. 111). A interpretação de que as partes representam pessoas ligadas por uma continuidade advém da necessidade de impedir o depauperamento de recursos face à representação por partes possivelmente desinteressadas na manutenção de recursos para a geração seguinte, o que leva Rawls ao princípio da poupança justa. Este princípio pode ser definido como o "entendimento entre gerações no sentido de que cada uma carregue a sua respectiva parte do ônus de realizar e preservar uma sociedade justa" (RAWLS, 1997, p. 327).

Kittay aponta que isto constitui uma séria constrição às concepções individuais de bem, contudo é um entendimento necessário - não irracional ou desarrazoado. Se é necessário um princípio para garantir que os recursos de uma geração não sejam depauperados na passagem para a outra, será também necessário um princípio similar para garantir o bem-estar dos dependentes e de seus cuidadores, uma vez que há fundamento para uma motivação nada mais que natural face ao conhecido processo de desenvolvimento humano, no qual há, pelo menos, duas fases de dependência - infância e velhice. Se as considerações intergeracionais são abordadas na teoria de justiça, seria de se esperar que elementos naturais da existência humana fossem igualmente endereçados - o que deixa de ser o caso face à idealização de Rawls de "parte" que representa uma pessoa livre, igual, independente e plenamente cooperável (1999, p. 83-88).

A segunda crítica de Kittay aborda a concepção de Rawls de sociedade bem organizada na qual todos são cidadãos inteiramente cooperativos, sendo estes os destinatários dos princípios de justiça. Os casos em que impedimentos de ordem mental ou física obstam esta plena cooperação ou geram gastos demasiados são considerados, em Rawls, moralmente irrelevantes para a concepção inicial dos princípios da justiça. Neste sentido, a adoção da

\footnotetext{
${ }^{26}$ Em Rawls: “as circunstâncias de justiça podem ser definidas como as condições normais sob as quais a cooperação é tanto possível quanto necessária. (...) Primeiro, existem as circunstâncias objetivas que tornam a cooperação humana simultaneamente possível e necessária. Assim, muitos indivíduos coexistem ao mesmo tempo em um mesmo território geográfico definido. (...) Em segundo lugar, há uma condição de escassez moderada implícita, para atender a uma ampla gama de situações. As circunstâncias subjetivas são os aspectos relevantes dos sujeitos da cooperação, das pessoas que trabalham juntas" (RAWLS, 1997. p. 136-137). 
norma de que todos são membros plenamente cooperativos durante o curso de uma vida dá plausibilidade ao modelo de cidadão da sociedade ideal como partes na posição original que estão simetricamente situadas $^{27}$. Kittay aponta que entre a idealização e a realidade, há o perigo de esta pressuposição colocar os dependentes e os cuidadores na pior posição ao priorizar a escolha de princípios de justiça apenas para os que funcionam independentemente, sem terem encargos de cuidado com outros. Isto porque o véu da ignorância não funciona como um dispositivo que evidencie estes estados naturais de dependência e de trabalho de dependência, uma vez que só abarca noções de cidadãos plenamente iguais e livres (KITTAY, 1999, p. 88-93).

Em terceiro lugar, Kittay avalia a pressuposição de Rawls que todos são plenamente capazes de entender e cumprir os princípios de justiça e de que, em virtude de sua liberdade, cada pessoa é uma fonte auto originária e auto autenticada de reivindicações válidas e justas. Para contestar a primeira noção - cada pessoa como uma fonte auto originária de reivindicações válidas -, a autora menciona a situação de uma mãe cuja reivindicação seja o direito à educação de seu filho ou filha. Do mesmo modo, os cuidadores também reivindicam - e têm o papel social de fazê-lo - garantias não para si, mas para os que deles dependem. Nesta situação, a liberdade na concepção de bem está vinculada a reivindicações originadas de outros, o que derroga a percepção do trabalhador de dependência - o cuidador - como uma fonte auto originária de reivindicações ${ }^{28}$.

Em relação à posterior alusão de Rawls aos indivíduos como auto autenticadores de suas reivindicações, Kittay argumenta que, de fato, o problema das reivindicações perpetradas por cuidadores em nome de dependentes, tais como o direito à educação, é resolvido por uma concepção ampliada do self. Contudo, a noção de que o papel de cuidador é escolhido livremente é contestada pela caracterização geminada e estereotipada da mulher como subordinada e como naturalmente cuidadora. Dessa forma, a liberdade enquanto fonte da auto autenticação pode não ser uma solução viável se a igualdade não permear a distribuição do

\footnotetext{
${ }^{27}$ Sobre a simetria, importante o aportado por Kittay: "The symmetries that allow the rational party to simulate the commitments of a rational and reasonable person do not hold for conditions pertinent to the dependency relation, and fail even on the weaker interpretation of the norm of full functioning. Whether we say that we are fully cooperating members of society throughout our lives, or over the course of our lives, the idealization is questionable at best, or pernicious at worst. Its virtues springs from the Kantian position that autonomy is that feature of human existence that gives our dignity. But it fosters a fiction that the incapacity to function as fully cooperating societal members is an exception in human life, not a normal variation; that the dependency is normally too brief and episodic to concern political life, rather than constituted by periodic, and often prolonged, phases of our lives who costs and burdens ought to be justly shared" (KITTAY, 1999, p. 92).

${ }^{28}$ Neste ponto, a autora faz a importante ressalva de que o desempenho pelo cuidador da reivindicação que se origina no outro deve vir da liberdade. Quando não vem, evidencia uma má estruturação não do trabalho de dependência, mas sim da noção de liberdade: "If dependedency work appears oppressive, it is because the norm of freedom is shaped without attention to the role of dependency in our lives" (KITTAY, 1999, p. 96).
} 
trabalho de dependência e, necessariamente, as questões distributivas afetas à dependência. Assim, a solução de Rawls finda por colocar o problema da dependência na esfera privada, estruturando um panorama em que reivindicações acreditadas como auto autenticadas são, na realidade, heterônomas, sem que se analise isto no bojo da justiça (KITTAY, 1999, p. 93-99).

Como quarta pressuposição Rawlsiana criticada, Kittay aborda a questão das duas faculdades morais - senso de justiça e concepção própria de bem - como pressupostos de bens primários indexados ${ }^{29}$. A pergunta da autora direciona-se à adequação do endereçamento possibilitado por esta lista de bens primários no que diz respeito aos que dependem e àqueles que cuidam desses, entendendo que uma releitura da teoria de justiça Rawlsiana que pretenda atender às questões propostas pelas demandas da dependência deve expandir a lista de faculdades morais e emendar a lista de bens primários. Quanto às faculdades morais, Kittay entende como necessária a inclusão da capacidade de responder à vulnerabilidade com cuidado $^{30}$. A partir da inclusão desta faculdade, há espaço para a concepção de bens que incluam, igualmente, o bem tanto de ser cuidado em uma relação de dependência responsável - quando e se uma pessoa não puder cuidar de si mesma - quanto o de responder às demandas de dependência dos outros sem incorrer em sacrifícios indevidos.

Por fim, como quinta crítica, Kittay aborda a concepção de cooperação que supõe a igualdade entre as partes em um sistema cooperativo. A cooperação social demanda, além da ação coordenada eficientemente organizada e guiada por regras reconhecidas, a existência de termos equânimes de cooperação, os quais são aceitados por seres racionais e razoáveis. Para Kittay, é racional e razoável incluir as questões da dependência nos termos equânimes de cooperação, dado que a dependência é um estado pelo qual todo e qualquer indivíduo, sem embargo de seu funcionamento total no momento da concepção dos princípios de justiça, estará pelo menos uma vez, além de poder vir a ser um cuidador. Neste sentido, a limitação do entendimento de cooperação social a interações entre pessoas completamente funcionais e independentes obscurece ou minimiza as contribuições dos dependentes - que, mesmo na sua dependência, contribuem para natureza contínua das relações humanas - e dos cuidadores $\left(\right.$ KITTAY, 1999, p. 105-109) ${ }^{31}$.

\footnotetext{
${ }^{29}$ A definição de bens primários em Rawls refere-se àquilo que as pessoas precisam para manter seus status de cidadãos livres e iguais e de membros sociais completamente cooperativos durante um período completo de vida. O autor aponta que os "bens sociais primários, em categorias amplas, são direitos, liberdades e oportunidades, assim como renda e riqueza", acrescendo, ainda, o "talvez o mais importante bem primário", qual seja a autoestima (RAWLS, 1997. p. 98, 487).

30 "A justice which does not incorporate the need to respond to vulnerability with care is incomplete, and a social order which ignores care will itself fail to be just" (KITTAY, 1999. p. 100-103).

${ }^{31}$ Neste ponto, Kittay desenvolve a ideia da interdependência a partir da expansão da noção de reciprocidades: "(...) we need a concept of interdependence that recognizes a relation - not precisely of reciprocity but of nested 
A partir da crítica a essas pressuposições, Kittay propõe que as condições pessoais de cada cidadão com deficiência não podem ser comparadas sob um parâmetro de normalidade predeterminado e específico. Contra Rawls e Nussbaum, Kittay defende que um enfoque de igualdade pautado em uma lista específica de capacidades ou na plena cooperação e funcionalidade não respalda a efetivação da plena participação das pessoas com deficiência em sociedade. Assim, a autora perfaz a crítica da igualdade pela interdependência ${ }^{32}$, propondo que todas as concepções de igualdade pautadas em um parâmetro de normalidade, indiferente à diferença, devem ser revistas sob o prisma da deficiência.

Concluímos apontando que, em Kittay, mesmo a interpretação mais liberal do esquema de Rawls não será suficientemente sensível às preocupações igualitárias e inclusivas em relação à deficiência. Para ela, a suposição de Rawls de que os participantes na posição original são ou representam membros totalmente produtivos da sociedade negligencia o fato de uma dependência humana generalizada e inevitável (WASSERMAN et al, 2013). É dessa forma que "aqueles envolvidos em relações de dependência são excluídos do perímetro conceitual do igualitarismo de Rawls" (1999, p. 79). De fato, a deficiência pode ser um exemplo especialmente poderoso de injustiça e exclusão epistêmicas, justamente porque as experiências desses sujeitos - especialmente daqueles com tipos específicos de deficiências são profundamente diversas das experiências do sujeito Rawlsiano, dotado de personalidade moral e engajado na posição original.

\section{Conclusão}

Os estudos sobre deficiência representam um grande desafio para os defensores da justiça Rawlsiana: a exclusão de pessoas com deficiência da posição original em que os indivíduos estão sob o véu da ignorância e as consequências disto para o funcionamento dos

dependencies - linking those who help and those Who require help to give aid to those who cannot help themselves" (1999, p. 107).

32 A noção de interdependência é mencionada, ainda, por Barbosa-Fohrmann et al quando trata dos direitos sociais a partir do modelo assistencialista, afirmando que "nesse modelo, existe uma ótica de cuidado, que enxerga as pessoas como entes sociais, interdependentes, que dão e recebem suporte e assistência durante suas vidas. (...) O reconhecimento e o respeito das condições de dependência, bem como o fomento às relações sociais e interconexões são parte da existência humana. Nesse sentido, a dependência não é um estado descartado de ser, é uma condição comum da vida, às vezes temporária, às vezes permanente. Além disso, por intermédio dela, podem ser revelados outros aspectos da humanidade: a conexão existente entre as pessoas, a necessidade que umas possuem das outras e a habilidade de prover cuidado". Ao fim, os autores destacam ainda a necessidade de assistência conduzir à independência, apontando um meio-termo entre os modelos assistencialista e liberal, a partir do qual "o cuidado é um recurso valioso, assim como receber cuidados deve ser visto como uma oportunidade de aumentar a independência e a escolha" (BARBOSA-FOHRMANN, 2012, p. 157-159). 
princípios de justiça derivados. Identificamos, em princípio, dois aspectos de consideração da noção de igualdade em Rawls ao tratarmos da deficiência: o estado da posição inicial, pautado na igualdade das partes representativas da teoria de justiça, e o segundo princípio de justiça, baseado nos princípios da igualdade equitativa de oportunidades e no princípio da diferença. Em seguida, analisamos duas teorias alternativas à Rawls, baseadas no enfoque das capacidades e na ética do cuidado.

Neste ponto, é preciso fazer a ressalva de que, em relação às pessoas com deficiência e, tendo por base uma conceituação totalmente desprovida de valorações e mais simplista, a "deficiência" enquanto falta ou ausência de eficiência pode mesmo ser considerada um caractere dos sistemas jurídicos baseados em teorias de justiça inaptas a albergar estes sujeitos. A deficiência jurídica, em uma analogia, configura-se na existência interna e estrutural de barreiras filosóficas e políticas, enfrentadas na tentativa de tratar com base na igualdade as pessoas com impedimentos de longo prazo de natureza física, mental, intelectual ou sensorial. Caso tais barreiras não sejam abordadas pela pesquisa jurídica, pode ser um desafio epistemologicamente intransponível o de garantir direitos a pessoas com deficiência, sobretudo as que tenham deficiências intelectuais, mentais e psicossociais severas - tais como o direito à educação com base na igualdade de oportunidades e não discriminação. Isto se aprofunda quando lidamos com a ideia de, por exemplo, efetivar esse direito de forma orientada à participação plena e efetiva em sociedade de indivíduos que nem mesmo na concepção inicial de justiça puderam fazer-se presentes.

\section{Referências}

ARISTÓTELES. Ética à Nicômaco. São Paulo. Nova Cultural: 1996.

BARBOSA-FOHRMANN, Ana Paula. Os modelos médico e social de deficiência a partir dos significados de segregação e inclusão nos discursos de Michel Foucault e de Martha Nussbaum. REI-REVISTA ESTUDOS INSTITUCIONAIS, v. 2, n. 2, p. 736-755, 2017.

; ANGELICA, Thiago da Costa Sá. Crianças com deficiência e o acesso à educação fundamental no Brasil: inclusão ou integração? Uma análise a partir do direito constitucional. Pensar-Revista de Ciências Jurídicas, v. 19, n. 1, p. 9-34, 2014.

BOBBIO, Norberto. Igualdade e Liberdade. 2. ed. Rio de Janeiro: Ediouro, 1997.

CARLSON, Licia; KITTAY, Eva Feder. Introduction: Rethinking philosophical presumptions in light of cognitive disability. Metaphilosophy, v. 40, n. 3 4, p. 307-330, 2009. 
CUENCA, Patricia. Disability and Humans Rights: A Theoretical Analysis. The Age of Human Rights Journal, n. 4, p. 34-59, 2015.

Sobre la inclusión de la discapacidad en la teoría de los derechos humanos. In: Revista de Estudios Políticos (nueva época). Madrid, n. 158, octubre-diciembre, 2012.

Derechos humanos y discapacidad: de la renovación del discurso justificatorio al reconocimiento de nuevos derechos. Anuario de filosofía del derecho, n. 32, p. 53-83, 2016.

DEGENER, Theresia. Disability in a Human Rights Context. Laws. vol. 5 no. 3. 2016.

DINIZ, Débora. Quem Autoriza o Aborto Seletivo no Brasil? Médicos, Promotores e Juízes em Cena. In: PHYSIS: Rev. Saúde Coletiva, Rio de Janeiro, 13(2):13-34, 2003.

FRENCH, Sally et al. Whose Tragedy: Towards a personal non-tragedy view of disability. In: SWAIN, John. et al (eds) Disabling Barriers - Enabling Environments. 2. ed. London: Sage, 2004.

KITTAY, Eva. Love's Labor: essays on women, equality and dependency. New York: Routledge. 1999.

KITTAY, Eva Feder. When caring is just and justice is caring: Justice and mental retardation. Public Culture, v. 13, n. 3, p. 557-579, 2001.

NUSSBAUM, Martha. The capabilities of people with cognitive disabilities. Metaphilosophy, v. 40, n. 3 4, p. 331-351, 2009.

NUSSBAUM, Martha C. Fronteiras da justiça: deficiência, nacionalidade, pertencimento à espécie. Tradução de Susana de Castro. São Paulo: WMF Martins Fontes, 2013.

RALWS, John. Justiça como eqüidade: uma concepção política, não metafísica. Lua Nova, São Paulo, n. 25, p. 25-59, Apr. 1992.

Ática. 2000.

O liberalismo político. Trad. Dinah de Abreu Azevedo. 2. ed. 2. Imp. São Paulo: ed.

Uma teoria de Justiça. Trad. Almiro Pisetta e Lenitta M. R. Esteves. São Paulo: Martins Fontes. 1997.

SHAKESPEARE, Tom. Disability rights and wrongs revisited. 2 ed. Londres, Nova York: Routledge. 2014.

SILVERS, Anita. Reconciling Equality To Difference: Caring (F)or Justice For People With Disabilities, Hypatia, v. 10, p. 30-55, 2009.

SILVERS, Anita; FRANCIS, Leslie Pickering. Justice through trust: Disability and the "outlier problem" in social contract theory. Ethics, v. 116, n. 1, p. 40-76, 2005.

Thinking about the good: Reconfiguring liberal metaphysics (or not) for people with cognitive disabilities. Metaphilosophy, v. 40, n. 3 4, p. 475-498, 2009. 
STEIN, Michael. Disability Human Rights, California Law Review, v. 95. N. 1, p. 75-121. 2007.

VITA, Álvaro de. Uma concepção liberal-igualitária de justiça distributiva. Revista Brasileira de Ciências Sociais, v. 14, n. 39, p. 41-59, 1999.

WASSERMAN, David et al. Disability and justice. In: Zalta, Edward N. et al (ed). The Stanford Encyclopedia of Philosophy. Palo Alto: Stanford University, 2013.

WONG, Sophia Isako. Duties of justice to citizens with cognitive disabilities. Metaphilosophy, v. 40, n. 3 4, p. 382-401, 2009. 